all show up anisotropy, and attempts are being made to interpret the results quantitatively.

Although largely devoted to the study of metals, the conference spent some time on topics related to semiconductors. N. F. Mott presented his theory of the transition to metallic conduction in semiconductors, regarding electronic transport in an impurity band as the jumping from site to site with activation by lattice vibrations. P. R. R. Aigrain, on the other hand, preferred a collective picture, in which the randomness of the distribution of impurity sites plays an important part. He suggested that certaiu states, although not localized, cannot carry current, and hence explained the low mobility in the impurity band. Experimental date on galvanomagnetic effects in $n$-type $\mathrm{InSb}$ at $4^{\circ} \mathrm{K}$. were given by $\mathrm{H}$. P. $R$. Frederikst. By considering valence bonds in various compounds, E. Mooser and H. W. B. Pearson were able to present some rules which allow the prediction of semiconducting properties.

An important contribution was made by A. F. Joffé, who discussed recent Russian work on heat conduction in semiconductors. Besides lattice conduction (which may be reduced very effectively by using mixed crystals so that phonons are scattered by the random distribution of atomic mass), there is a significant electronic contribution, and also a further part which may be due to transport of heat by excitons. This led to considerable discussion, with opinions divided as to the exact interpretation.

J. M. ZIMAN

\section{GAS TURBINE DEVELOPMENT}

$T$ HE Engineering Department of the North Herts Technical College, Letchworth, arranged a conference on "Gas Turbine Development", which was held during October 20-21. It attracted more than a hundred, most of whom were leading designers or research workers in the appropriate field.

The first of the four main papers was given by Mr. G. B. R. Feilden, engineering director, Messrs. Ruston and Hornsby, Ltd., who offered a brief résumé of the development of the Ruston and Hornsby gas turbine $(750 / 1,000 \mathrm{~kW}$.), since 1946 , dealing particularly with the engineering difficulties which were experienced in putting the research designs into working order. At the end of $1,500 \mathrm{hr}$. running experience with this machine, it was decided to go ahead with a production model capable of $750 \mathrm{~kW}$. and rising to $1,000 \mathrm{~kW}$. maximum output. Improvements were made in the prototype output by raising the maximum temperature, and increasing the length of the turbine blades by 7-8 per cent; production economy being maintained by utilizing tooling for existing blades. It was decided, also, to improve the matching of the components and make minor adjustments to the burners. The completed model had a compressor and turbine practically identical with the prototype, though epicyclic gears had been introduced and the turbine mounting improved. In order to enable the individual components to be serviced easily, however, considerable modifications in layout had been incorporated.

Mr. Feilden illustrated developments in the more recent installations, including one at Milan, which has now been in continuous operation for $10,000 \mathrm{hr}$. This machine is fired by natural gas, and the arrange- ment of the combustion chambers with ancillary ducting has proved very practicable for servicing. $\mathrm{He}$ also illustrated the installation at Debden, in which the heat exchanger is placed below the set, and the combustion chamber is arranged at an angle downwards. This is a coal-tar fuel-burning set with the ducting arranged upwards. Another slide showed the installation at the Admiralty Test House at Pyecroft, which was made to exacting specifications, the air inlet in this installation being at an unusual angle, and the ducting was woven through the installation. The turbine is to be fitted with a heat exchanger made of corrugated steel plates in the near future.

Mr. Feilden concluded his address by comparing the overall efficiencies of various plants required to produce both power and process steam. The Diesel is the most efficient power producer, and, for a $1,000-\mathrm{kW}$. electrical output, used in conjunction with an exhaust heat boiler, it gives better figures than any other plant for outputs of process-steam up to 7,500 lb. per hr.; above that requirement, the gas turbine is better. An exclusively steam plant, even with a highly efficient steam turbine and a high. pressure water-tube boiler, is far behind in overall efficiency, and only begins to be competitive if a very considerable quantity of steam (more than 20,000 lb. per hr.) is asked for.

Discussion revealed that problems of servicing under varying climatic and atmospheric conditions have been extremely interesting. While the installation at Kuwait has to digest large quantities of sand, this appears to have no adverse effect upon the turbine blades. The sodium sulphate in airborne particles presents an entirely different problem with the Milan installation, and it is necessary to wash the blades every $200-300 \mathrm{hr}$. with a solution of 'Teepol' and water; the turbine has now done $3,000 \mathrm{hr}$. non-stop.

"The Marine Gas Turbine" was the subject of the second paper, by A. W. Pope, chief gas turbine engineer, Messrs. W. Allen, Sons and Co., Ltd. Mr. Pope showed that there are two distinct applications of the marine gas turbine-naval and merchant marine. In connexion with naval applications, there are many differing requirements. Naval can be divided into two categories: $(a)$ protection of convoys, and $(b)$ task forces. The former duty is performed mainly by frigates, a comparatively new class of ship of which there are various types (fast escort, anti-submarine, anti-aircraft and air direction). The task force duties are undertaken by aircraft carriers and cruisers. The varying requirements mean that aircraft carriers spend much of their time at full power, whereas frigates spend very little. On one such ship, it was found that 70 per cent of full power was used for only 1 per cent of the ship's life. 'There is here an obvious application for gas turbines (known as boost turbines) to provide the extra power when required. Already two British ships have been provided with such turbines, and an American ship is powered by 9,000 steam h.p., and 21,000 gas turbine h.p., with a saving of 20 per cent on engine weight.

Gas turbines are also being used for electrical generation. There are two types of generator set, namely, emergency and base-load. In emergency sets, fuel consumption is unimportant, and the gas turbine correspondingly simple. Mr. Pope gave an example of the development of such a turbine, detailing various changes in design to give greater efficiency. 
Of base-load generator sets, he said that these will undoubtedly become standard practice in the Navy, possessing as they do several advantages over diesel sets, to which they are preferred above $350 \mathrm{~kW}$. Mr. Pope then gave details of a 1,000-kW. base-load generator set and of a $500-\mathrm{kW}$. set.

On merchant marine applications, Mr. Pope remarked that engines for this purpose operate their whole life at full power, and, due to the cost of running, only one experimental set has so far been built. He gave figures, however, to prove that maintenance costs are much lower than those for diesel engines, and possibly than those of steam turbines. There is, he said, a certain amount of interest in emergency gas turbine generator sets for the merchant marine. One such machine has been developed; it was first run only 21 months after the initiation of the project, and was delivered after only 26 months.

"Air Development" was the theme of an address by Dr. A. W. Morley, head of Forward Projects Investigations Department, Messrs. D. Napier and Sons, Ltd. Dr. Morley traced the development of the gas turbine engine, dating from Dr. A. A. Griffiths (1926), who applied Prof. Frankel's theory of circulation, to the turbo-prop and jet engines which are known to-day. The piston-engine transport, he said, belongs to the past, and he showed a short film of the conversion of the piston-engine transport to the turbo-prop transport (Convair 340). 'The reasons for the conversion became evident as the lecture developed ; namely, it provided a saving of weight and an increase of power, so that the cruising speed went up as well as the pay-load. This conversion utilized the Eland turbo-prop engine, and Dr. Morley justified the title of his lecture by describing in detail the principles and development of the above engine, including the control system, fuel metering system and torque meter. He also dealt with some of its safety aspects, detailing the maximum torquemeter, and overspeed governor, stressing the fact that the ideal design is such that if one part fails something else comes into play.

Dr. Morley then showed how the introduction of new conceptions brings about new machines, as for example in the Fairey Rotodyne (rotor, 90 ft. diameter), Rolls-Royce "Flying Bedstead" and in helicopter development.

Applications to the motor vehicle were dealt with by Dr. J. H. Weaving, chief research engineer, Austin Motor Co., who described the main steps in development, with slides showing the calculations and results represented in graphical form.

The importance of the heat exchanger was emphasized, and it was shown that there is no point in having high compression ratios if a heat exchanger is used. Dr. Weaving compared the efficiencies of the gas turbine with heat exchanger, petrol and diesel engines at full load; it is possible to achieve efficiencies with gas turbines comparable with the diesel engine if a thermal ratio of 0.9 is used, and comparable with the petrol engine if a thermal ratio of 0.7 is used.

Dr. Weaving stated that research is continuing on rigs to improvo the efficiency of individual components. A centrifugal compressor has been on test, and axial compressors of single, two and three stages have been tried. A two-stage compressor giving ratios of 4 to 1 and 6 to 1 without overstressing has been used, and a three-stage compressor is now in service. Research into the design of burner and combustion chamber is being carried out by J. Lucas and Co., Ltd.

Dr. Weaving foreshadowed great developments in the regenerative types of heat exchangers, and concluded his address with illustrations of the result of researches in Great Britain, the United States and on the Continent. The installation of the Austin turbine in the "Princess" saloon was shown, also the G.T. 302 "Whirlfire" and its novel installation with twin-disk regenerative heat-exchanger as fitted in the General Motors "Firebird".

\section{SUMMER SCHOOL IN PHYSICS IN THE UNIVERSITY OF MEXICO}

IST summer the University of Mexico held, for 1 the first time, a summer school in physics. The subject on this occasion was theoretical nuclear physics, and the course extended from July 9 until the end of August. The twenty-eight members of the school were mostly graduate students or senior staff in theoretical physics, but also included some experimental physicists. Apart from members of the University of Mexico there were visitors from the Argentine (2), Brazil (3), Cuba (1), Britain (1), France (2), Germany (1), India (1) and the United States (9).

Unesco provided for the travelling expenses of some of the members, others had grants from their own national institutions, and in addition a good deal of local expenditure was borne by the University of Mexico.

The meetings, which were conducted in English, were held in the Physics Department of the University (director, Prof. C. Graef Fernandez) and the programme was designed and arranged by Dr. M. Moshinsky, professor of theoretical physics.

The idea of such a summer school bear's some relation (and no doubt has received some inspiration) from the successful summer schools that have become regular institutions in Les Houches (France) and Varenna (Italy); but the Mexican Summer School differed from these older institutions by being rather more specialized. The five lecture courses provided all dealt with parts of nuclear theory; their subjects were: collective motions in nuclei (M. Moshinsky); theory of nuclear reactions (R. G. Thomas) ; electromagnetic reactions with nuclei (J. S. Levinger); the nuclear shell model (B. Stech); and nuclear forces (R. E. Peierls). Thus they covered specialized and well-defined sections of the subject, and with about, twenty-four lectures in each course it was possible to present each topic in fair detail. The lectures were given on three mornings and two afternoons each week. In addition, there was a weekly seminar in which the topics ranged rather more widely, and by request of the members of the School a short series of lectures by Prof. Graef Fernandez on general relativity.

One of the obvious functions of such a course was to give some inspiration and encouragement to the young, but growing, group of theoretical research workers at the University of Mexico, and one had the impression that the members of this group appreciated the opportunity of taking part in a live discussion of modern topies from a variety of points of view. 'They took part in the lectures and discussions with great enthusiasm, in spite of the language difficulty, which must have demanded of some of them as great or greater effort than the 